\title{
DIMENSIONAL AND JUDGMENTAL DETERMINANTS OF ILLUSIONS OF VISUAL SIZE ${ }^{1}$
}

\author{
KEN SHIINA ${ }^{2}$ AND ROBERT B. FREEMAN, JR.
}

University of Konstanz

\begin{abstract}
The influence of modified forms of the Ponzo-illusion figure and densitygradient patterns on the apparent size of lines and circles was investigated. Consistent with previous repors, the predictions of constancy scaling theory were not confirmed. The results are shown to be dependent both on visual size-comparison mechanisms and judgmental variables.
\end{abstract}

Among the various theories that have been put forward in recent times to account for optical illusions, one of the best known is the theory of depth processing. This approach has recently been elaborated by Tausch (1954) and Gregory (1963, 1964, 1965), and has been called " inappropriate constancy scaling" (Gregory, 1963). The basic notion of the theory is that illusions represent flat projections of three-dimensional objects that are common to everyday visual experience, and that the visual illusions resemble the perspective distortions of the retinal projections of objects and contours in three-dimensional space. Assuming a mechanism of perceptual constancy "scaling" that responds directly to such visual features, the perceived visual distortions resulting from illusion figures can be ascribed to the same mechanism that contribute to visual constancy.

In this connection, Gregory (1963) distinguishes between primary and secondary constancy scaling. Primary constancy scaling is determined by perspective or

1 This research was supported by NIMH Grant 10,691 and University of Konstanz Grant 33: 73 to the second author. The experimental portion of this investigation was conducted in the Department of Psychology, Pennsylvania State University, University Park, Penna., U.S.A.

${ }^{2}$ Requests for reprints should be sent to Ken Shiina, Fachbereich Psychologic, Universität Konstanz, 775 Konstanz, Federal Republic of Germany. other features normally associated with distance in the three-dimensional world, and does not necessarily implicate perceived distance. Thus, distortions of visual illusions occur in spite of the fact that the elements of such illusions are seen to occur in a single plane.

Secondary constancy scaling, according to Gregory, implies an involvement of apparent distance. The size of an object is determined at least in part by its perceived distance. An example of the effectiveness of secondary constancy scaling, according to Gregory, is the variable perceived size of a visual after-image when projected onto surfaces at different actual (and therefore perceived) distances. Secondary constancy scaling is clearly ruled out in the visual illusions, where sufficient cues are present to indicate that the elements of the illusion figures are coplanar.

The constancy scaling theory has been subjected to repeated experimental attack (Humphrey \& Morgan, 1965; Gillam, 1973; Fisher, 1968; Robinson, 1968; Brown \& Houssiadas, 1964). Although there are a number of theoretical issues yet to be clarified, at least three experimental conditions have been reported in which the postulates of the constancy scaling theory cannot be applied to explain the experimental results. It is therefore not surprising that a variation of the constancy scaling theory, the "general constancy theory", has also been proposed 
(Day, 1972). According to this position, " any stimulus which serves to maintain perceptual constancy of a property of an object as the visual representation of that property varies will, when independently manipulated with the retinal image not varied, produce an illusion" (Day, 1972, p. 1340). This theory has the advantage of being stated in a more general form and is, therefore, less dependent upon the specifics of linear perspective as a cue to visual distance. Of particular interest here are several demonstrations which show that visual size comparisons can produce illusory distortions of perceived size (cf. also Massaro \& Anderson, 1971) without the involvement of perspective-like figures.

Alternative theories of the illusions have been investigated by many authors. Among those that have received recent experimental attention are the eye-movement, the contrast and the judgmental theory. According to the eye-movement theory, the apparent length of lines is determined by the extent of effort of eye movements required to scan their physical length (Brandt, 1944). The relation between the eye movements and apparent length has been confirmed by Yarbus (1967). However, the theory itself has been disconfirmed in experiments in which it was shown that certain illusions occur even under conditions of retinal image stabilization (Pritchard, 1958; Yarbus, 1967) or when the illusion-producing figures were exposed for brief periods so as to preclude eye movements (Lewis, 1902).

The contrast theory as applied to visual illusions has been expressed in at least two different forms which are analogous to usages with reference to brightness contrast (cf. Freeman, 1967). The first usage, made explicit by Helmholtz, was that "in all perceptions of the senses distinctly perceptible differences appear to be larger than differences of the same objective sizes which are only vaguely perceived " (Southall, 1962, III, p. 192). This principle was used by Helmholtz to account for, among other things, the Oppel-Kundt filled-space illusion, and has been applied in the investigation of Zöllner's illusion by Benussi (1902), of the concentric circles illusion by Oyama (1962; Oyama \& Akatsuka, 1962) and of a variation of the Ponzo illusion by Fisher (1969).

The contrast theory is more frequently defined in the sense used by von Kries which, in modern terms, states that the appearance of a single element may be displaced away from the appearance of another spatially (or temporally) proximal element along a given continuum (von Kries, 1962, p. 239; Humphrey, 1971). This principle has been opposed to another, related principle, which is variously called confluence (Müller-Lyer, 1896; von Kries, 1962; Virsu, 1967) or assimilation (Morinaga, 1935), according to which elements that lie adjacent to each other on a given continuum appear more similar than their physical differences would predict.

Finally, the judgmental theory suggests that illusory effects can be attributable to variations in the judgmental attitudes of the observer under different observing conditions. For example, Morinaga (1958) has found a paradoxical displacement in illusion figures like those of Ponzo, Hering and Müller-Lyer when judgments were carried out in different ways. The Hering illusion may be cited as an example: When the parallel lines (Fig. la) of the standard Hering figure were replaced by parallel rows of dots (Fig. lb), the direction of the illusion was unaltered. How-
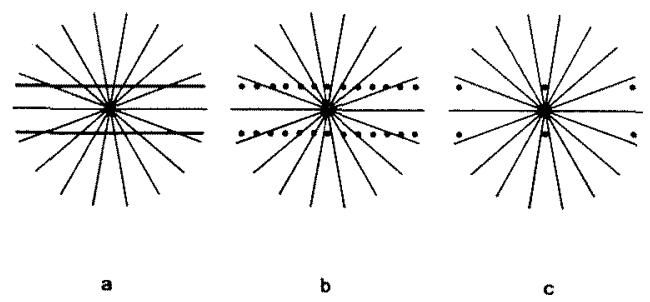

Fig. 1. An example of the paradoxical illusion proposed by Morinaga (1958). 
ever, when the parallel lines were replaced by three pairs of dots separated by equal distances (Fig. 1c), the direction of the illusion was reversed. Morinaga concluded that the difference in the results was attributable to the different kinds of judgments used, which was called "dimensions of judgment": In Fig. la and $1 \mathrm{~b}$, the "direction" of lines was judged, while in Fig. 1c the "distance" between the pairs of dots were judged. Presumably different perceptual mechanisms underly the two types of judgments.

In the investigations reported below, two groups of illusion figures were chosen so as to enable an experimental evaluation of the contrast, constancy scaling, and judgmental theories of illusions. The background or " inducing" elements of the figures were derived from the Ponzo illusion and a gradient pattern introduced by Gibson (1950). The test and comparison figures (lines and circles) were also chosen to maximize the power of the experimental procedures among the various theorics mentioned ${ }^{3}$.

\section{EXPERIMENT}

\section{Method}

Subjects. Two groups of seven university undergraduates ( 3 men and 4 women) from an introductory psychology course at Pennsylvania State University served as subjects. All showed normal visual acuity (better than 18/20) with both far and near vision as determined with a Titmus optical vision tester.

Stimulus figures. Nine figures were used altogether. Five of them were variations of the Ponzo illusion (Fig. 2a, b, c, d and Fig. 3) and four were representations of the gradient figure introduced by Gibson (1950, p. 89) (Fig. 4a, b, c, d). The converging lines of

These experiments were conducted at Pennsylvania State University in 1971. More recently an experiment has been reported by Gillam (1973) whose methods and results were, in important respects, highly similar to parts of the study reported here.
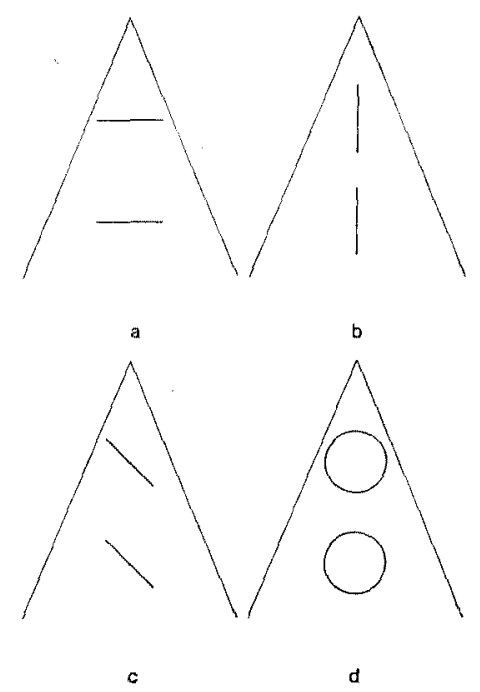

FIG. 2. The Ponzo illusion figure and variations used in this experiment.

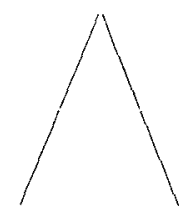

Fic. 3. Additional variation of the Ponzo figure."

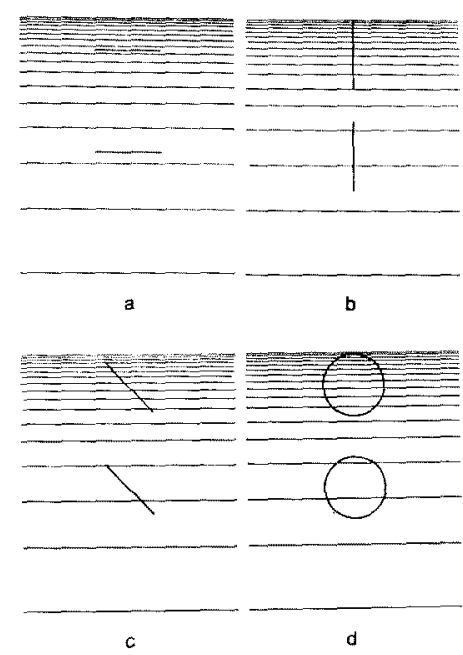

FrG. 4. The density gradient figures used to show the size illusion effects.

4 The authors are greatly indebted to Takeo Iida for his suggestion of this variation of the Ponzo figure. 
the Ponzo figure lay at an angle of $45 \mathrm{deg}$ to each other and converged to a point at the center of the top edge of the stimulus card. Line width was about $.8 \mathrm{~mm}$. The topmost line of the gradient figure was positioned $20 \mathrm{~mm}$ below the upper edge of the stimulus card. In this figure, line width was about $.5 \mathrm{~mm}$. All figures were drawn with "India ink" on white posterboard $(17 \times 15 \mathrm{~cm})$, and were positioned at a distance of $115 \mathrm{~cm}$ from the observer's eye.

The test figures used with both types of backgrounds were a pair of horizontal lines (Fig. $2 \mathrm{a}$ and $4 \mathrm{a}$ ), vertical lines (Fig. 2b, 4b), diagonal lines rotated $45 \mathrm{deg}$ from the horizontal (Fig. $2 c$ and $4 c$ ), and circles (Fig. $2 d$ and $4 d$ ). Line width of all the test figures was about $.8 \mathrm{~mm}$. The length (diameter) of the upper test figures was held constant at $40 \mathrm{~mm}$ (about 2 deg visual angle), and the center of the figure was positioned $60 \mathrm{~mm}$ below the top edge of the card. The size of the lower test figure was varied in 2-mm steps. The test figures were separated by about $60 \mathrm{~mm}$.

An additional figure (Fig. 3) consisted only of two pairs of lines which were separated by a 1-mm space. The length of the upper pair of lines was held constant at $60 \mathrm{~mm}$, while the lower pair was variable from 50 to $70 \mathrm{~mm}$ in 2-mm steps.

In the control conditions, the test figures were exposed without the backgrounds used in Figs. 2 and 4. The control figure for Fig. 3 consisted of two pairs of parallel lines separated by a $1-\mathrm{mm}$ space as in the experimental condition.

Procedure. All figures were exposed for $2 \mathrm{sec}$ each in one channel of a Scientific Prototype, 3-channel tachistoscope (Model GB). Between exposures $S$ fixated a dot positioned in the center of a card in a second channel. The horizontal and vertical visual-angle dimensions of the stimulus cards were approximately $8^{\circ}$ and $6^{\circ}$ respectively. Luminance of the stimulus cards was $1.5 \log \mathrm{ftL}$. Observation was binocular, and a chin holder was used to position $S$ 's eye-level at the center of the field. All figures were easily discriminable.

The control trials were run before the experi- mental trials with all $S$ s. One group of seven $S$ s was tested with the modified Ponzo figures (Fig. 2a, b, c, d and 3), the other with the gradient figures (Fig. 4a, b, c, d). The order of the figures was randomized across $S$ s. The instructions required $S$ s to judge whether the longer line (larger circle) was at the top or the bottom. "Same" answers were not permitted.

The staircase method was used to determine the sequence of comparison-stimulus size (Cornsweet, 1962). The procedure was continued until 6 determinations of apparent equality between the standard and variable stimulus sizes had been determined for each subject and stimulus condition.

\section{Results}

Illusion index. The index of illusion is defined by

$$
\mathrm{I}(\%)=100 \times(\mathrm{T}-\mathrm{C}) / \mathrm{C}
$$

where $T$ was the matched size of the test figure in an illusion condition and $\mathrm{C}$ was the matched size of the test figure in the corresponding control condition.

The Ponzo illusion. The results of the four conditions of the Ponzo illusion (Fig. $2 a, b, c, d)$ are shown for individual subjects in the first four columns of Table 1 . The largest illusion was obtained in the standard condition (horizontal test lines; Fig. 2a). In this condition the upper horizontal line was overestimated by $12.4 \%$. An intermediate amount of illusion (about $4 \%$ in each case) was obtained when the diagonal lines and the circles were used as test figures (Fig. 2c and $2 \mathrm{~d}$, respectively). The illusion using vertical lines as test figures (Fig. 2b) was insignificant.

The results of a statistical comparison of all possible pairs of the Ponzo figures are shown in Table 2. The horizontal test lines produced a significantly larger illusion than any other test condition. Both the diagonal lines and the circles yielded a stronger illusion than the vertical lines, but were not significantly dif- 
TABLE 1

Error in percent of the mean control setting for each experimental subject

\begin{tabular}{|c|c|c|c|c|}
\hline & \multicolumn{4}{|c|}{ Ponzo figures } \\
\hline & $2-\mathrm{a}$ & $2-b$ & $2-\mathrm{c}$ & $2-d$ \\
\hline$S(11)$ & 8.64 & 3.79 & 5.50 & 5.64 \\
\hline$S(12)$ & 17.07 & 2.56 & 4.88 & 6.00 \\
\hline$S(13)$ & 16.45 & 2.56 & 6.25 & 5.55 \\
\hline$S(14)$ & 10.90 & 0 & 4.88 & 2.50 \\
\hline$S(15)$ & 12.10 & -1.26 & 3.32 & 4.88 \\
\hline$S(16)$ & 10.56 & -2.59 & 0 & 1.97 \\
\hline$S(17)$ & 11.11 & -1.23 & 3.33 & 5.64 \\
\hline Mean & 12.40 & .54 & 4.02 & 4.60 \\
\hline s & 3.16 & 2.41 & 2.02 & 1.52 \\
\hline \multirow[t]{3}{*}{$t \dagger$} & $10.33 * * *$ & .59 & $5.09 * *$ & $7.42 * *$ \\
\hline & \multicolumn{4}{|c|}{ Gradient figures } \\
\hline & $4-a$ & $4-b$ & $4-c$ & $4-d$ \\
\hline$S(21)$ & -.61 & 5.00 & -.51 & .49 \\
\hline$S(22)$ & 0 & 4.94 & 2.00 & .61 \\
\hline$S(23)$ & 1.40 & 6.75 & 2.50 & 1.23 \\
\hline$S(24)$ & 2.50 & 9.55 & 6.30 & 5.60 \\
\hline$S(25)$ & 1.88 & 9.55 & 5.00 & 3.12 \\
\hline$S(26)$ & 2.50 & 6.66 & 3.66 & 2.34 \\
\hline$S(27)$ & 0 & 8.13 & 2,00 & 2.50 \\
\hline Mean & 1.10 & 7.23 & 2.99 & 2.27 \\
\hline s & 1.29 & 1.93 & 2.23 & 1.77 \\
\hline$t^{\dagger}$ & 2.24 & $10.04 * * *$ & $3.52 *$ & $2.95^{*}$ \\
\hline \multicolumn{5}{|c|}{$\begin{array}{l}\text { Note: } * p<.05, * * p<.01, * * * p<.001 \text { (two } \\
\text { tail), } \dagger t=\overline{\mathrm{D}} /\left((\mathrm{D}-\overline{\mathrm{D}})^{2} / n(n-1)\right)^{1 / 2} \text { where } \overline{\mathrm{D}} \text { is } \\
\text { mean error in percent; } \mathrm{D} \text { is error in percent; } \\
\text { and } n \text { is the number of subjects. }\end{array}$} \\
\hline
\end{tabular}

ferent from each other. The illusion of the vertical lines was not significantly different from zero (Table 1).

The gradient figure. The results of the four conditions in which the gradient figure was used are shown in the last four columns of Table 1. In this case the maximum illusion was given by the vertical lines and was significantly larger than any other test condition. Moreover, the horizontal test lines did not produce a significant amount of illusion. The illusion with diagonal lines and circles assumed intermediate values, although much smaller than those obtained with the Ponzo figure.
TABLE 2

Statistical comparison of figure pairs (Ryan's method: .05 level)

\begin{tabular}{|c|c|c|c|c|}
\hline & \multicolumn{4}{|c|}{ Ponzo figures } \\
\hline & $2-\mathrm{a}$ & $2-b$ & $2-c$ & $2-d$ \\
\hline $2-a$ & $x$ & $*$ & $*$ & $*$ \\
\hline $2-\mathrm{b}$ & & $x$ & $*$ & $*$ \\
\hline $2-c$ & & & $x$ & - \\
\hline \multirow[t]{3}{*}{$2-d$} & & & & $x$ \\
\hline & \multicolumn{4}{|c|}{ Gradient figures } \\
\hline & 4-a & $4-b$ & $4-c$ & $4-d$ \\
\hline $4-a$ & $x$ & $*$ & $*$ & $*$ \\
\hline $4-b$ & & $x$ & $*$ & $*$ \\
\hline $4-c$ & & & $x$ & - \\
\hline $4-d$ & & & & $x$ \\
\hline Note: & .05 & .05 & & \\
\hline
\end{tabular}

Statistical comparisons for all possible pairs of figures using the gradient background are shown in Table 2. The illusion with the vertical test lines was significantly greater than any other condition. All other comparisons yielded significant differences except between the circles and the diagonal lines (Ryan's test).

Converging lines. In this test (Fig. 3), the expectation according to the constancy scaling theory would suggest that the upper lines should appear significantly greater than the lower lines, at least to the extent that they appear farther away (secondary constancy scaling). In fact, the upper lines appeared significantly shorter (negative illusion) than the lower lines when compared to the control condition using parallel lines $(t=3.57, p<.05$; two-tailed test).

\section{Discussion}

The results of these experiments provide strong evidence in favor of an explanation of illusions that is inconsistent with the constancy scaling theory. The constancy scaling theory suggests that the upper figure in all of the test figure pairs used 
here should be seen significantly larger than the lower figure of the pair. The expected results were, however, not obtained in the critical tests involving Fig. $2 \mathrm{~b}$ and $4 \mathrm{a}$, and the outcome of the test using Fig. 3 was significantly in the wrong direction.

The theory of inappropriate constancy scaling would also have to predict that no significant differences would be obtained among the variations of the teststimulus conditions within Fig. 2 and within Fig. 4. On the contrary, substantial and statistically significant differences were obtained between the conditions of Fig. $2 \mathrm{a}$ on the one hand and $2 \mathrm{c}$ and $2 \mathrm{~d}$ on the other, and between Fig. $4 \mathrm{a}$ in comparison with Figs. $4 \mathrm{c}$ and $4 \mathrm{~d}$.

Similarly it is possible to derive predictions from the contrast theory which are only in part consistent with the results obtained in this experiment. According to contrast theory (von Kries, 1962) and its variations (e.g. Day, 1972) one would expect that the upper test figures would appear larger than the lower ones in all conditions in which an appropriate visual comparison is possible. These conditions would include Figs. 2a, c, d and Figs. $4 \mathrm{~b}, \mathrm{c}, \mathrm{d}$, but not $2 \mathrm{~b}, 4 \mathrm{a}$, and 3 . However, there is no reason to expect differences in the amount of illusion between the conditions of Fig. 2a, 2c, and 2d or the conditions of Fig. 4b, 4c, and 4d. Since substantial differences were obtained between the results using Fig. $2 \mathrm{a}$ on the one hand and Fig. $2 c$ and $2 \mathrm{~d}$ on the other, as well as between Fig. $4 \mathrm{~b}$ versus Fig. $4 \mathrm{c}$ and $4 \mathrm{~d}$, the involvement of other judgmental variables in the discrimination task is suggested.

Morinaga (1958) has alluded to the danger of overapplication of the concept of size contrast without consideration of judgmental dimensions involved in the discrimination concerned. In our experiment, size contrast can affect only the horizontal component of the test figures in Fig. $2 \mathrm{c}$ and $2 \mathrm{~d}$, and the vertical com- ponent of the test figures in Fig. $4 \mathrm{c}$ and 4d. Since diagonal lines and circles can be divided into both horizontal and vertical components, only one of the two possible components in the judgmental task can be affected by the illusion-producing elements of figures.

We conclude therefore that the illusion obtained with the circle and diagonal lines represents a pooling of two judgmental effects involved in the comparison of the two figures. First, the two test figures are compared directly with each other, as in the control conditions used in this experiment, as far as the vertical component (height) in Fig. $2 \mathrm{c}$ and $2 \mathrm{~d}$ and the horizontal component (width) in Fig. 4c and $4 \mathrm{~d}$ are concerned. Without the influence of the illusion-producing components of the figure, this comparison is relatively accurate. Secondly, each of the two test figures is compared visually with the adjacent elements of the illusion-producing components of the figure, producing a strong illusion through size contrast for the horizontal component of all relevant test figures in Fig. 2 and the vertical component of the relevant test figures in Fig. 4.

In the conditions of Fig. $2 \mathrm{~b}$ and $4 \mathrm{a}$, the conditions favorable to contrast are lacking while the conditions for teststimulus comparison are excellent. In the conditions of Fig. 2a and 4b, the conditions for contrast are nearly optimal while the conditions for the test-stimulus comparison are no more favorable than in Fig. $2 b$ and $4 \mathrm{a}$. In the other four conditions the conditions of contrast and test-stimulus comparison are both favorable so that an intermediate result is obtained.

Finally, consistent with the results of Gillam (1973), we found that the illusion using the appropriate form of the Ponzo figure (Fig. 2a) was substantially and significantly greater than the illusion using the appropriate form of the gradient figure $(t=3.42, d f=12, p<.01$; two tailed test. Fig. 4b). This suggests that gradient perspective itself is a weaker determinant of 
apparent size than linear perspective confirming previous reports of similar comparison with size (Leibowitz, Brislin, Perlmutter \& Hennessy, 1969) and slant (Freeman, 1969; Gillam, 1968).

In general, we conclude that an appropriate theoretical interpretation of the magnitude of illusions must include a consideration of the judgmental disposition of the observer (Morinaga, 1958). When the test components of an illusion figure are presented without the illusion-producing elements (corresponding to reduction conditions in a size- or shape-constancy experiment), retinal-image size of the test and comparison figures will determine the observer's responses. When the background includes elements relevant to the illusory effect, and the judgment of the observer is based on these elements, an illusion will occur.

Of particular interest is the fact that size comparisons in the figures we used produced an illusory effect only when the contrast-producing comparisons were along the same dimension. Thus, vertical lines in the Ponzo figure and the horizontal lines on the gradient figure result in " retinal image matching" because the test figures cannot be judged on the same figural dimensions as the illusion-producing elements. This finding provides a viable alternative to the inappropriate constancy scaling hypothesis and a useful specification of a contrast explanation of visual illusions.

\section{REFERENCES}

Benussi, V. 1902 Über den Einfluss der Farbe auf Grösse der Zöllner'schen Täuschung. Zeitschrift für Psychologie, 29, 264-351; 385433.

BRANDT, H. F. 1944 The psychology of seeing.New York: Philosophical Library.

Brown, L. B., \& Houssiadas, L. 1964 Illusory perception as a constancy phenomenon. $\mathrm{Na}$ ture, 204, 302.

Connsweet, T. N. 1962 The staircase-method in psychophysics. American fournal of Psy- chology, 75, 485-491.

DAy, R.H. 1972 Visual spatial illusions: A general explanation. Science, 175, 1335-1340.

Fisher, G. H. 1968 An experimental and theoretical appraisal of the inappropriate size-depth theories of illusions. British foumal of Psychology, 59, 373-383.

Fisher, G. H. 1969 Towards a new explanation for the geometrical illusions. I. The properties of contours which induce illusory distortion. British Journal of Psychology, 60, 179185.

Freeman, R. B., Jr. 1967 Contrast interpretation of brightness constancy. Psychological Bulletin, 67, 165-187.

Freeman, R.B., Jr. 1969 Cue-relevance and the psychophysical metric of retinal perspective and density gradients in the discrimination of slant. Paper presented at the Eastern Psychological Association, Philadelphia, Penna., April 10.

Grsson, J.J. 1950 The perception of the visual world. Boston: Houghton Mifflin.

GrLlam, B. 1968 Perception of slant when perspective and stereopsis conflict: Experiments with aniseikonic lenses. Journal of Experimental Psychology, 78, 299-305.

Gillam, B. 1973 The nature of size scaling in the Ponzo and related illusions. Perception and Psychophysics, 14, 353-357.

GreGory, R. L. 1963 Distortion of visual space as inappropriate constancy scaling. Nature, 199, 678-680.

Gregory, R. L. 1964 Reply to Brown and Houssiadas. Nature, 204, 302-303.

GREGORY, R. L. 1965 Reply to Humphrey and Morgan. Nature, 206, 744-745.

HumpHrey, N. K. 1971 Contrast illusions in perspective. Nature, 232, 91-93.

Humphrey, N. K., \& Morgan, M.J. 1965 Constancy and the geometric illusions. Nature, 206, 744-745.

KrIes, J. von 1962 Notes by v. Kries on $\$ 28$. In J. P. C. Southall (Ed.), Helmholtz's treatise on physiological optics. New York: Dover, Vol. III, pp. 232-242.

Leibowttz, H., Brislin, R., Perlmutter, L., \& Hennessy, R. 1969 Ponzo perspective illusion as a manifestation of space perception. Science, 166, 1174-1176.

LEwis, E. O. 1902 The effect of practice on the perception of the Müller-Lyer illusion. British Journal of Psychology, 2, 294-306.

Massaro, D.W., \& Anderson, N.H. 1971 
Judgmental model of the Ebbinghaus illusion. Journal of Experimental Psychology, 89, $147-151$.

Morinaga, S. 1935 The conditions for size-assimilation and -contrast. Festschrift for Dr. Masuda: A collection of current psychological papers. Tokyo: Iwanami, Pp. 28-48 (in Japanese).

MorinaGA, S. 1958 Über die Raumwahrnehmung in Hinsicht auf die optischen Täuschungen. Proceedings of the XVth International Congress of Psychology, Pp. 273-274.

Müller-Lyer, F. C. 1896 Uber Kontrast und Konfluxion. Zeitschrift für Psychologie, 9, 1$16 ; 10,421-431$.

Oyama, T. 1962 The effect of hue and brightness on the size-illusion of concentric circles. American Fournal of Psycholog v, 75, 45-55.

Oyama, T., \& Akatsuka, R. 1962 The effect of hue and brightness on the size-illusion of concentric circles: A further study. Japanese
Psychological Research, 4, 129-134.

Prrtchard, R. M. 1958 Visual illusions viewed as stabilized retinal images. Quarterly Journal of Experimental Psychology, 10, 77-81.

Robinson, D. O. 1968 Retinal inhibition in visual distortion. British Journal of Psychology, 59, 29-36.

Southale, J.P.C. 1962 Helmholtz's treatise on physiological optics. New York: Dover.

Tausch, R. 1954 Optische Täuschungen als artifizielle Effekte der Gestaltungsprozesse von Größen- und Formen-Konstanz in der natürlichen Raumwahrnehmung. Psychologische Forschung, 24, 299-348.

Vtrsu, V. 1967 Contrast and confluxion as components in geometric illusions. Quarterly Fournal of Experimental Psychology, 9, 198-207.

YARBUS, A.L. 1967 Eye movements and vision. New York: Plenum.

(Received July 10, 1974) 